\title{
La mediación intralingüística: propuestas didácticas
}

\author{
MontesarRat CAÑAda PuJOLS \\ Àrea d'Idiomes-EOI \\ mcanada2@xtec.cat \\ STEFANIA FANTAUZZI \\ Àrea d'Idiomes-EOI \\ sfantauz@xtec.cat \\ MARIA TRULLÀs SOLER \\ Àrea d'Idiomes-EOI \\ mtrulla7@xtec.cat
}

Resumen: Los principales objetivos de este artículo son definir el concepto de mediación intralingüística y presentar propuestas didácticas para practicar y/o evaluar esta actividad de lengua en los niveles B1, B2 y C1. Nuestro trabajo se enmarca en el contexto de las Escuelas Oficiales de Idiomas de Cataluña. La publicación de los Reales Decretos 1041/2017 y 1/2019 impuso a las EEOOII evaluar la mediación lingüística. Como asesoras técnicas coordinadoras de las pruebas de certificación en las EEOOII catalanas, llevamos a cabo una investigación para definir el concepto de mediación, desarrollar los currículos, determinar las características de las tareas de mediación intralingüística y elaborar criterios de evaluación. Las muestras de tareas y las escalas de evaluación que presentamos en este artículo son fruto del estudio realizado. Gracias a esta investigación hemos podido constatar la validez de las tareas de mediación intralingüística y la complejidad que supone redactarlas y evaluarlas.

Palabras clave: mediación, intralingüística, Companion Volume, evaluación.

\section{Intralinguistic mediation: didactic proposals}

Abstract: The main objectives of this article are defining the concept of intralinguistic mediation and presenting didactic proposals to practice and/or assess this language activity at levels B1, B2 and C1. Our research is framed in the context of the Escuelas Oficiales de Idiomas (EEOOII), Official Language Schools, in Catalonia. The publication of Royal Decrees 1041/2017 and 1/2019 forced the EEOOII to assess linguistic mediation. As technical advisors coordinating the certification tests in the Catalan EEOOII, we carried out research to define the concept of mediation, develop curricula, determine the characteristics of intralinguistic mediation tasks and develop assessment criteria. The samples of tasks and the assessment scales that we present in this article are the result of the study performed. Thanks to this research, we have been able to verify the validity of intralinguistic mediation tasks and the complexity of writing and assessing them.

Key words: mediation, intralinguistic, Companion Volume, assessment. 


\section{La mediación lingüística en las Escuelas Oficiales de Idiomas}

Las Escuelas Oficiales de idiomas (EEOOII) son organismos públicos dedicados a la enseñanza y la certificación del nivel de dominio de las lenguas tanto del territorio nacional como de lenguas extranjeras. Con la publicación de los Reales Decretos 1041/2017 de 22 de diciembre y 1/2019 de 11 de enero cambió la normativa que regula los currículos y las pruebas de certificación de las EEOOII. Con el primero se establece el currículo de los niveles Intermedio B1, Intermedio B2, Avanzado C1, y Avanzado C2 de las Enseñanzas de idiomas de régimen especial y con el segundo se establecen los principios básicos comunes de evaluación aplicables a las pruebas de certificación oficial de los niveles Intermedio B1, Intermedio B2, Avanzado C1 y Avanzado C2 de las enseñanzas de idiomas de régimen especial.

Unos de los cambios con más repercusión que implicó la nueva normativa fue la aparición de la mediación lingüística como actividad de lengua que pondera un $20 \%$ del total de las pruebas de certificación de B1, B2, C1 y C2, junto con la comprensión oral, la comprensión escrita, la expresión e interacción oral y la expresión e interacción escrita que ponderan el $80 \%$ restante a partes iguales.

El concepto de mediación aparece ya en el MCER (Council of Europe, 2001: 14), pero es en el CEFR. Companion Volume with new Descriptors (North, Goodier, Piccardo, Stathopoulou, 2018: 105), a partir de ahora Companion Volume, donde la mediación adquiere una dimensión más amplia. Mientras que el MCER hace hincapié en la traducción y la interpretación como medios para facilitar la comunicación entre personas que no se pueden comunicar directamente, el Companion Volume (North, Goodier, Piccardo, Stathopoulou, 2018: 106) va un paso más allá y añade aspectos como la construcción y la transmisión de significado.

Se trata de un enfoque que considera que el/la mediador/a debe interpretar el significado de lo dicho o escrito, incluyendo significados que los interlocutores pueden no entender o malentender, y adaptar este significado para ayudar a los participantes a comprender (Dendrinos, 2006: 10-11).

El término, en líneas generales, tiene que ver con la «acción de poner en comunicación a dos o más interlocutores o grupos de personas que por varios motivos no logran comunicarse directamente» (Trovato, 2013: 107).

Como asesoras técnicas del Departament d'Educació de la Generalitat de Catalunya en el Àrea d'idiomes-EOI hemos trabajado para introducir la mediación en los currículos y también en las pruebas certificadoras. La perspectiva de nuestro trabajo y de nuestra investigación, por lo tanto, está muy centrada en las pruebas de certificación de lenguas y en la opción intralingüística, ya que Cataluña se ha inclinado por este tipo de mediación en las pruebas de certificación mismas.

Para empezar, comentaremos las características y el papel de la mediación intralingüística, subrayando los aspectos de nuestro trabajo que consideramos más originales para contribuir a la definición del concepto de mediación, de sus particularidades y de las estrategias que se utilizan en las actividades de mediación. A partir de estas consideraciones, pasaremos a indicar cómo deberían ser las tareas de mediación y propondremos unas reflexiones sobre uno de los aspectos más complejos relativos a la mediación: la evaluación. En este marco presentaremos modelos de 
actividades de mediación y propuestas de evaluación.

La introducción de la mediación lingüística en las pruebas de certificación ha requerido un trabajo de investigación, redacción, pilotaje y validación de las pruebas y de los criterios de evaluación. Este proceso de elaboración se ha basado en la lectura de la literatura sobre el tema y en los intercambios de opiniones y resultados con los/las compañeros/as, investigadores/as y expertos/as sobre mediación. Por eso, en este texto presentamos unas propuestas que repasan nuestro recorrido desde una perspectiva que tiene en consideración tanto los aspectos teóricos como los prácticos.

\section{La mediación intralingüística}

Es fácil asociar el concepto de mediación con el de traducción o interpretación (Sanchez Castro, 2013: 793; Trovato, 2013: 106), ya que parece lógico que alguien que no conoce una lengua extranjera necesite a un/a mediador/a que le traduzca o le transmita el contenido del mensaje que no logra entender. En este caso se trata de mediación interlingüística (cross-linguistic mediation), en la que la mediación implica un cambio de código, es decir, pasar de una lengua A a una lengua B. Algunas investigaciones llevadas a cabo distinguen entre mediación interlingüística textual o escrita (la traducción) y mediación interlingüística personal u oral (la interpretación) (Cantero Serena y de Arriba García, 2004: 7-9). Veamos un ejemplo para aclarar el concepto de mediación interlingüística: queremos comprar unos billetes para el tren Flecha Roja pero la página web está solo en ruso y necesitaremos a un hablante de este idioma para que nos facilite los contenidos del texto que son relevantes para nosotros.

A veces, a pesar de que el/la destinatario/a y el/la mediador/a comparten el mismo código lingüístico, puede surgir la necesidad de mediar. En este caso se trata de mediación intralingüística. La mediación intralingüística (intra-linguistic mediation) es la que requiere transmitir en una lengua una información de un input oral, visual, escrito o multimodal, en esa misma lengua y hacerla llegar al/a la destinatario/a que no la ha entendido o no ha tenido acceso a la información por el motivo que sea (Cañada, Fantauzzi y Trullàs, 2019: 106). En este caso el input (o texto fuente) está en la misma lengua del/de la destinatario/a, pero puede cambiar el canal, el género textual o el registro del texto output. Lo ilustraremos con otro ejemplo: somos alumnos/as de alemán y un día no podemos asistir a clase, por eso le pedimos a un/a compañero/a de curso que nos haga un resumen de un video que vieron en clase el día que no pudimos ir.

La literatura sobre el tema que se aborda en este capítulo ha evidenciado la distinción entre mediación interlingüística e intralingüística. Ya el MCER (Council of Europe, 2001: 99) señalaba esta diferencia entre los dos tipos de mediación, es decir, entre hablantes de idiomas diferentes o de un mismo idioma, subrayando explícitamente que la mediación no se limita a la mediación interlingüística.

Algunas fuentes bibliográficas abogan a favor de la mediación interlingüística y la definen como el proceso mediante el cual un usuario (el mediador) extrae algunas informaciones concretas de un texto (input) en un idioma, código o dialecto y los transmite en otro idioma, código o dialecto con un objetivo comunicativo concreto (Dendrinos, 2006: 16-17). A pesar de que, según Dendrinos (2006: 20), la mediación no es necesariamente una actividad que implique dos idiomas diferentes, en los exámenes KPG del Ministerio de Educación de Grecia, que han sido coordinados por ella durante 
más de 15 años, puede apreciarse una clara apuesta por la mediación interlingüística. El texto fuente es en griego para las pruebas de todas las lenguas extranjeras. Se presupone, por lo tanto, que los/as candidatos/as dominan el idioma griego, como mínimo a nivel de comprensión $\mathrm{y}$, en cierta, manera estas pruebas evalúan también la habilidad de comprender textos en griego. Stathopoulou (2014: 351), por su parte, apunta en la misma dirección y considera la mediación como «una práctica social que se produce para facilitar la comunicación entre las partes que no comparten el mismo idioma»y hace especial énfasis en el aspecto de la comunicación intercultural para hacer frente a las experiencias cotidianas de las sociedades multilingües de hoy en día (Stathopoulou, 2016: 760), asimismo, señala la complejidad de la naturaleza de la mediación interlingüística, y justifica la elección de esta opción en los exámenes KPG ya que

los cambios derivados de la globalización crean la necesidad de comunicar efectivamente en diferentes situaciones interculturales (...) y es muy probable que una persona deba actuar como mediador/a, por ejemplo, ejerciendo de puente lingüístico y cultural entre personas que no comparten el mismo idioma". (Strathopoulou 2016: 760)

La mediación es un aspecto que se está trabajando en las aulas y ya se empieza a tener constancia de experiencias y actividades de clase interlingüísticas muy interesantes. Sin embargo, para los exámenes de certificación de Cataluña, no se consideró que fuera viable una prueba con un input en un idioma y un output en otro. Evidentemente, el texto producido sería en la LE, pero se descartó esta opción para las Pruebas de Certificación de EEOOII de la comunidad autónoma de Cataluña por la siguiente serie de motivos. La primera gran cuestión fue constatar que las pruebas de certificación de les EEOOII certifican únicamente el nivel de dominio de la lengua extranjera sobre la que el/la candidato/a se examina. En ningún caso se certifica el conocimiento de la L1 o de cualquier otra lengua. En segundo lugar, en Cataluña existe la cooficialidad del catalán y el castellano. Optar por la mediación interlingüística hubiera dificultado la elaboración y administración de las pruebas ya que a los/las candidatos/as se les habría tenido que suministrar el input en ambos idiomas. Esto hubiera complicado la elaboración de las pruebas ya que se habrían tenido que traducir textos y maquetar las pruebas en la versión catalana y la versión castellana $\mathrm{y}$, además, habría sido poco práctico a la hora de administrar la prueba, ya que cada candidato/a debería haber tenido derecho a escoger qué versión de la prueba deseaba. Pero además nos encontramos ante otra cuestión. La tercera razón por la que se optó por la mediación intralingüística es que, si bien la gran mayoría del alumnado de nuestros centros son catalanes/españoles que asisten a aprender una lengua extranjera, también es cierto que cada vez más hay en las aulas alumnado con una L1 distinta al catalán o el castellano. Incluir input en catalán o castellano habría sido un agravio para ellos, respeto al alumnado que tiene estas lenguas como L1. Hay aún una razón más que se explica a partir del caso del catalán para no-catalanohablantes y del español lengua extranjera. Aquí el problema es evidente, porque nos encontramos ante alumnado de diversas nacionalidades y lenguas maternas y hubiera sido difícil decidir en qué lengua hubiera tenido que recibir el alumnado el texto fuente. Habría sido imposible facilitar a cada alumno/a el texto input en su lengua materna y no habría sido justo ofrecerles únicamente los textos en inglés, ya que su nivel de dominio del inglés podría ser muy heterogéneo. Esta habría sido una prueba de certificación con una dificultad añadida difícil de gestionar.

Por estos motivos, en las Escuelas Oficiales de Idiomas catalanas nos hemos posicionado a favor de la mediación intralingüística en las pruebas de certificación, a pesar de que 
somos conscientes que las tareas intralingüísticas dificultan la evaluación del descriptor de mediación del Companion Volume la Facilitating intercultural space (North, Goodier, Piccardo, Stathopoulou, 2018: 122) e imposibilitan la evaluación del descriptor Translating (North, Goodier, Piccardo, Stathopoulou, 2018: 113).

Cada una de las tareas que proponemos en el apartado 5 evalúa un descriptor de mediación del Companion Volume (North, Goodier, Piccardo, Stathopoulou, 2018: 104). Las tareas que presentamos abarcan la gran mayoría de descriptores exceptuando Note taking y Translating, por lo que a actividades de Mediating a text se refiere.

\section{El diseño de las tareas de mediación}

A continuación, mostraremos un esquema-resumen de las principales características que deben tener las tareas de mediación (Figura 1). Queremos destacar cuatro aspectos principales que seguidamente comentaremos: el input, el/la destinatario/a, el contexto y el/la mediador/a.

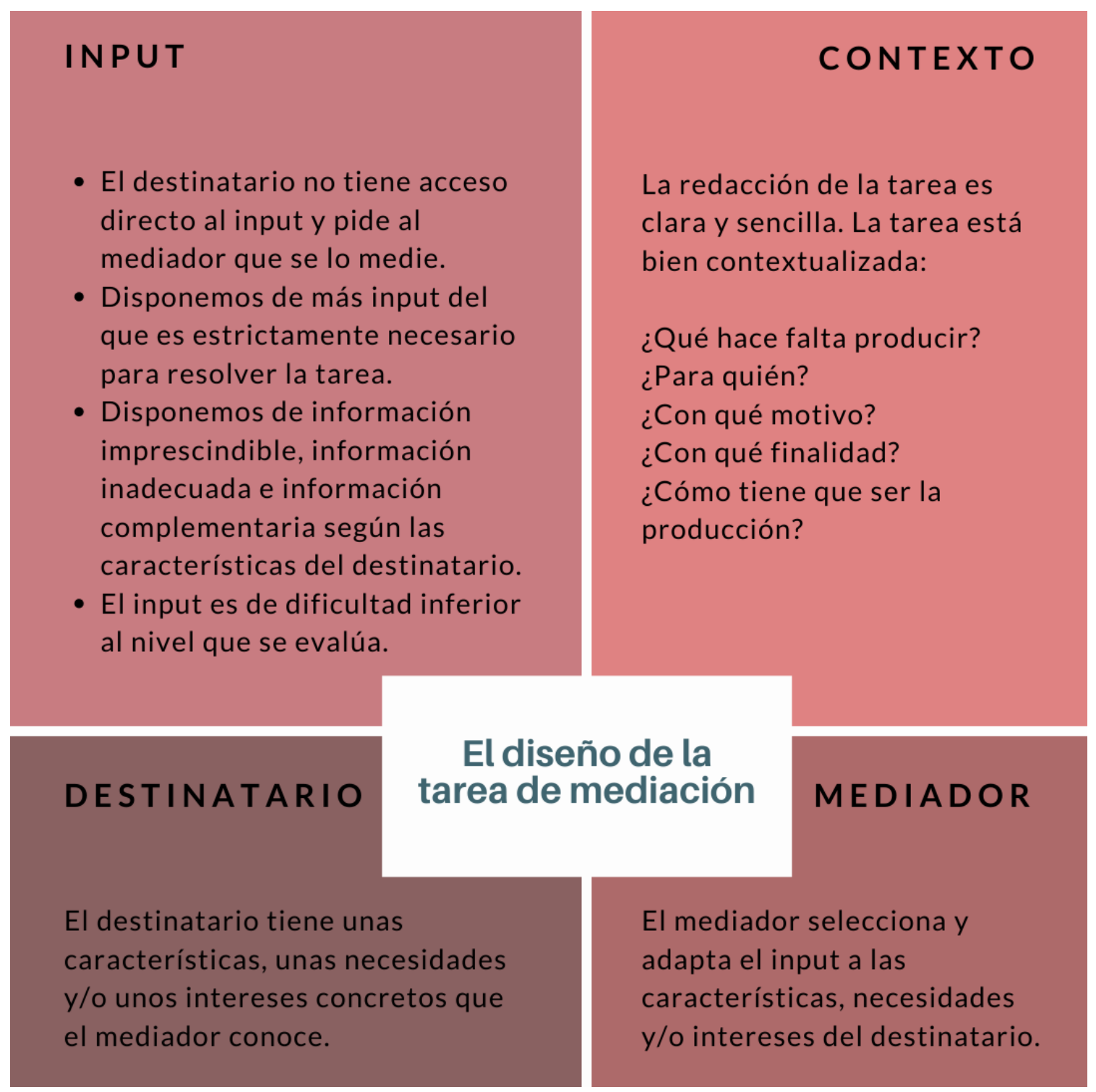

Imagen 1. El diseño de la tarea de mediación. Diseño de las autoras. 
En primer lugar, el input es la información a la que el/la destinatario/a no tiene acceso. Puede que no la entienda porqué está en otro idioma o por falta de conocimientos técnicos, o puede que no la tenga delante justo en ese momento. Esta información puede proceder de un interlocutor presente, pero puede ser también una información visual, oral, escrita o multimodal. En cualquier caso, el/la destinatario/a pide al/a la mediador/a que le transmita la información del input que sea relevante para él/ella.

Para que el/la mediador/a pueda escoger de entre todas las informaciones de las que dispone, aquellas que interesen al/a la destinatario/a, el input contendrá más input del que es estrictamente necesario para resolver la tarea. Debemos disponer de información imprescindible, información inadecuada e información complementaria según las características del/de la destinatario/a. De esta manera el evaluador podrá valorar positivamente la transmisión de información específica relevante para el/la destinatario/a, valorar negativamente la transmisión de información inadecuada para el/la destinatario/a y valorar la información complementaria en función de la argumentación que el/la mediador/a aporte. El aspecto de la selección de información es primordial en mediación, ya que si no se requiere selección, lo que el/la alumno/a produce es un resumen o una transmisión de la información principal del input como se venía haciendo hasta ahora. No cualquier tarea que movilice las estrategias de mediación (reformular, ampliar la información, sintetizar, etc.) será una tarea de mediación. Para que lo sea es imprescindible que el/la mediador/a tenga que seleccionar información.

Un último aspecto que hace falta tener en cuenta, por lo que al input se refiere, es la dificultad que este presente al/la alumno/a. Dado que para la habilidad de la mediación lo que se evalúa no es la comprensión escrita u oral, es recomendable que el input sea de dificultad inferior al nivel de lengua que se evalúa. También es aconsejable que este input sea en forma de prompts, o sea palabras clave, si el descriptor del Companion Volume que se evalúa es el de Relaying specific information (North, Goodier, Piccardo, Stathopoulou, 2018: 107). Hemos observado en las primeras producciones de mediación que hemos recogido, que si el input contiene largas frases, hay más tendencia a copiar información del input en lugar de reformularla.

En segundo lugar, toca definir muy bien el/la destinatario/a, ya que será en función de las características de este que el/la mediador/a seleccionará la información relevante a transmitir. Recomendamos definir unas tres necesidades. Menos de tres pueden ser insuficientes para llevar a cabo un diálogo de mediación y tener suficiente información para discutir. Más de tres necesidades del/de la destinatario/a obligan a tener un input muy largo, lo que dificulta la preparación de la tarea ya que el enunciado se alarga y la dificultad cognitiva de la tarea aumenta. Veremos ejemplos en el apartado 5.

En tercer lugar, contextualizaremos la tarea. La redacción de la tarea tiene que ser clara, sintética y sencilla. Todos los detalles que no sean relevantes para la selección de información por parte del/de la mediador/a tienen que ser eliminados con el objetivo de simplificar el enunciado. Las siguientes cinco preguntas nos ayudan a definir el contexto: ¿Qué hace falta producir? ¿Cómo tiene que ser la producción? ¿Para quién? ¿Con qué motivo? ¿Con qué finalidad?

Y en cuarto y último lugar, está el/la mediador/a que, como ya hemos dicho, seleccionará y adaptará el input a las características y necesidades del/de la destinatario/a. Si la redacción del enunciado es clara el/la alumno/a no va a tener dificultad en entender la tarea, aunque este no esté familiarizado con el concepto de la mediación lingüística. 


\section{Pautas para la evaluación de la mediación}

Uno de los aspectos más complejos de la mediación es su evaluación, ya que las tareas de mediación implican diferentes aspectos no únicamente lingüísticos, sino también cognitivos, de carácter social, cultural, etc. Desarrollar descriptores para evaluar la mediación significa así encontrar la forma para hacer visible esta compleja conceptualización que está detrás de las actividades y de las estrategias utilizadas.

En la investigación que hemos llevado a cabo para redactar las escalas para la evaluación de la mediación nos ayudó la rúbrica ${ }^{1}$ elaborada por la región de Alemania de SchleswigHolstein para evaluar las competencias de mediación escrita en lengua extranjera en pruebas similares a las correspondientes a nuestro acceso a la universidad. La rúbrica contiene tres bloques: la gestión del contenido y la estructura, la gestión de la interacción y la interculturalidad y la gestión de los elementos lingüísticos.

El análisis de la rúbrica de Schleswig-Holstein y de los elementos presentes en las tareas de mediación de las pruebas de mediación que hemos pilotado y administrado nos ha llevado a identificar cuatro criterios para evaluar la mediación: 1. la gestión del contenido/gestión del texto, 2 . la gestión de la situación comunicativa, 3 . la gestión de la interacción y creación del contenido y 4 . la gestión de la lengua. La gestión del contenido tiene que ver con el input a mediar, o sea, con la actividad mediating a text del Companion Volume (North, Goodier, Piccardo, Stathopoulou, 2018: 107): implica la selección de la información y su reproducción, reorganización y transformación según las características textuales del producto requerido. Este criterio está vinculado con el criterio que tiene que ver con la gestión de la situación comunicativa (que corresponde a la actividad de mediating comunication del Companion Volume (North, Goodier, Piccardo, Stathopoulou, 2018: 122). De hecho, la gestión de la situación comunicativa implica tener en cuenta la situación, el contexto y/o el papel asignado para resolver la tarea, las características del/de la destinatario/a, los referentes interculturales y las explicaciones necesarias culturalmente. El tercer criterio tiene que ver con la gestión de la interacción y a las actividades que el Companion Volume indica como mediating concepts (North, Goodier, Piccardo, Stathopoulou, 2018: 117). Tiene que ver con la facilitación y el liderazgo de la interacción y con la construcción conjunta de significado. El último criterio, la gestión de la lengua, tiene que ver con los aspectos lingüísticos de la prueba: riqueza y corrección en el uso de estructuras y vocabulario, pronunciación, etc. Este último criterio se puede contemplar de manera explícita o integrar en los otros. Depende de cómo se pretenda desarrollar la rúbrica de evaluación.

Esta cuestión nos lleva a reflexionar sobre cómo construir la rúbrica, si de forma holística o analítica. Teniendo en cuenta las características de las actividades, de las estrategias y de las tareas de mediación, parece más oportuno evaluar siguiendo una rúbrica holística. Un modelo de este tipo, de hecho, responde por un lado a los diferentes criterios que hemos propuesto y por otro refleja el carácter complejo de la mediación y las diferentes

${ }_{1}$ En le siguiente enlace se puede consultar la rúbrica del Land Schleswig-Holstein, en Alemania, para la mediación escrita del inglés como lengua extranjera en el Abitur (el equivalente a la EBAU, Evaluación de Bachillerato para el Acceso a la Universidad):

https://za.schleswigholstein.de/zabDokumente/?view=101\&path=Abitur|2022\&dHash=b122400148db5b 8 fa477e758a13977d5 
competencias que integra. En este sentido, consideramos que la evaluación de los aspectos lingüísticos no necesita de un criterio aparte, ya que se puede evaluar en la reorganización y estructuración de la información. Asimismo, aunque la cuestión intercultural no esté explícita en el descriptor, su dominio se evalúa implícitamente ya que si el/la mediador/a no tiene en cuenta los referentes interculturales no se podrá adaptar correctamente a la situación comunicativa planteada.

Por lo tanto, el descriptor de la banda más alta de una rúbrica holística de cinco bandas para la mediación escrita podría ser el siguiente:

\begin{tabular}{|c|l|}
\hline Puntos & \multicolumn{1}{|c|}{ Modelo holístico: Criterios de mediación escrita (ME) } \\
\hline 5 & $\begin{array}{l}\text { Selecciona toda la información relevante del input y la adapta de manera } \\
\text { eficaz al/a la destinatario/a y a la situación comunicativa. Reorganiza y } \\
\text { estructura la información de manera clara y convincente. Utiliza con mucha } \\
\text { seguridad las estrategias necesarias para llevar a cabo la tarea (reformula, } \\
\text { resume, parafrasea, añade explicaciones, etc.). Desarrolla activamente y } \\
\text { adecuadamente la tarea y la construcción del contenido y del significado. }\end{array}$ \\
\hline
\end{tabular}

Para la mediación oral el descriptor tendría que ser diferente, ya que hay que tener en cuenta también los descriptores del Companion Volume, Facilitating collaborative interaccion with peers y Collaborating to construct meaning (North, Goodier, Piccardo, Stathopoulou 2018: 118) que no se pueden evaluar en tareas no interaccionales, como la mediación escrita. El descriptor podría ser el siguiente:

\begin{tabular}{|c|l|}
\hline Puntos & \multicolumn{1}{|c|}{ Modelo holístico: Criterios de mediación oral (MO) } \\
\hline 5 & $\begin{array}{l}\text { Selecciona toda la información relevante del input y la adapta de manera } \\
\text { eficaz al/a la destinatario/a y a la situación comunicativa. Reorganiza y } \\
\text { estructura la información de manera clara y convincente. Utiliza con mucha } \\
\text { seguridad las estrategias necesarias para llevar a cabo la tarea (reformula, } \\
\text { resume, parafrasea, añade explicaciones, etc.). Colabora activamente al } \\
\text { desarrollo de la tarea y a la construcción del contenido y del significado. } \\
\text { Facilita y lidera la interacción, tomando la iniciativa de manera autónoma } \\
\text { cuando es necesario. }\end{array}$ \\
\hline
\end{tabular}

El modelo holístico responde mejor al constructo de las tareas de mediación, pero en la práctica de la evaluación hemos constatado unas dificultades en el uso de una escala holística, sobre todo en el momento de discernir los diferentes aspectos a tener en cuenta. Por eso proponemos también una escala analítica que desmenuza los diferentes aspectos de la escala holística y evalúa los aspectos lingüísticos en los descriptores de la transmisión de los contenidos: 


\begin{tabular}{|c|c|c|c|c|}
\hline \multicolumn{5}{|c|}{ Modelo analítico: Criterios de mediación escrita (ME) } \\
\hline $\mathrm{El} / \mathrm{La}$ candidato/a $\ldots$ & 4 & 3 & 2 & 1 \\
\hline selecciona e interpreta... & $\begin{array}{l}\text { toda la información } \\
\text { relevante del input }\end{array}$ & $\begin{array}{l}\text { gran parte de la información } \\
\text { relevante del input }\end{array}$ & $\begin{array}{l}\text { parcialmente la información } \\
\text { relevante del input }\end{array}$ & $\begin{array}{l}\text { No selecciona la información } \\
\text { relevante del input }\end{array}$ \\
\hline $\begin{array}{c}\text { adapta el discurso al/a la } \\
\text { destinatario/a, a sus } \\
\text { necesidades y a la } \\
\text { situación } \\
\text { comunicativa... }\end{array}$ & de manera eficaz & en general de manera eficaz & $\begin{array}{l}\text { de manera no demasiado } \\
\text { adecuada y poco eficaz }\end{array}$ & con muchas dificultades \\
\hline $\begin{array}{l}\text { transmite y estructura la } \\
\text { información... }\end{array}$ & $\begin{array}{l}\text { con detalle, de manera clara } \\
\text { y concisa, utilizando un } \\
\text { lenguaje preciso y variado }\end{array}$ & $\begin{array}{l}\text { con bastante detalle, de } \\
\text { manera suficientemente clara } \\
\text { y concisa, utilizando un } \\
\text { lenguaje bastante preciso y } \\
\text { variado }\end{array}$ & $\begin{array}{l}\text { con poco detalle, a menudo de } \\
\text { manera confusa, utilizando un } \\
\text { lenguaje poco preciso y } \\
\text { variado }\end{array}$ & $\begin{array}{l}\text { No consigue transmitir la } \\
\text { información. Su lenguaje no } \\
\text { es preciso ni variado }\end{array}$ \\
\hline $\begin{array}{l}\text { utiliza las estrategias } \\
\text { necesarias para llevar a } \\
\text { cabo la tarea... } \\
\text { (comparar, contrastar, } \\
\text { resumir, parafrasear...) }\end{array}$ & con mucha seguridad & con (bastante) seguridad & con inseguridad & $\begin{array}{l}\text { con dificultad y limitaciones } \\
\text { evidentes }\end{array}$ \\
\hline $\begin{array}{c}\text { desarrolla la tarea y } \\
\text { construye contenido... }\end{array}$ & $\begin{array}{l}\text { activamente, promoviendo } \\
\text { la interacción cuando es } \\
\text { necesario }\end{array}$ & $\begin{array}{l}\text { con algo de inseguridad, } \\
\text { promoviendo la interacción } \\
\text { con cierta autonomía }\end{array}$ & $\begin{array}{l}\text { con dificultad, promoviendo } \\
\text { la interacción de manera } \\
\text { esporádica. }\end{array}$ & $\begin{array}{l}\text { muy esporádicamente, } \sin \\
\text { promover la interacción }\end{array}$ \\
\hline TOTAL: ___ / 20 & & & & \\
\hline
\end{tabular}


En el caso de la MO, dado que se tiene que tener en cuenta el aspecto interactivo, el último descriptor se sustituye por el siguiente: "Colabora al desarrollo de la tarea y a la construcción del contenido». El/la mediador/a obtendría 4 puntos si mediara activamente, facilitando la interacción, 3 puntos si lo hiciera con algo de inseguridad, facilitando la interacción con cierta autonomía, 2 puntos si lo hiciera con dificultad, facilitando la interacción de manera esporádica y 1 punto en el caso que lo hiciera muy esporádicamente, sin facilitar la interacción.

\section{Ejemplos comentados de tareas de mediación intralingüística}

En este apartado nos proponemos mostrar ejemplos comentados de tareas de mediación intralingüística para los niveles B1, B2 y C1. Serían, por lo tanto, tareas para alumnos/as de español como lengua extranjera.

\subsection{Mediación escrita de B1: Plan Barbastro Joven}

Esta actividad el/la alumno/a la llevará a cabo de forma individual y dispondrá de 30 minutos para resolverla, si le queremos evaluar.

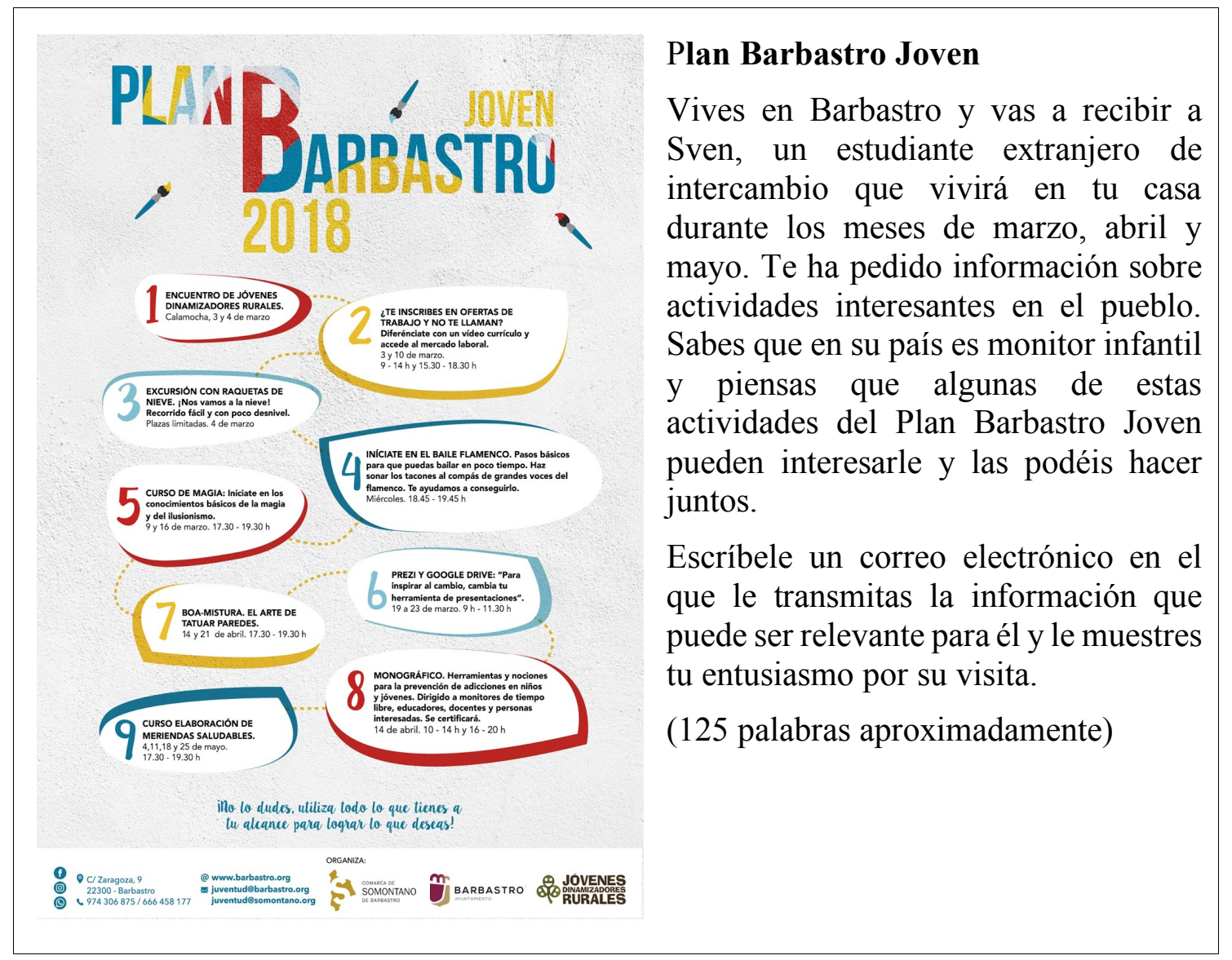

Imagen 2: Plan Barbastro Joven 2018. Fuente: http://juventudsomontano.blogspot.com/p/programacionjuvenil.html 
El/La alumno/a deberá producir un correo electrónico de 125 palabras para Sven, un estudiante extranjero de intercambio que vivirá en su casa durante los meses de marzo, abril y mayo, porque le ha pedido ayuda y para transmitirle las actividades del Plan Barbastro Joven que como monitor infantil puedan interesarle.

Para esta tarea se ha escogido un contexto claro, sencillo y bien contextualizado en el que el/la mediador/a recibe la visita de alguien de fuera. Esta persona por estar fuera del país no tiene acceso a la información y pide ayuda, por lo tanto, tiene que ser el/la mediador/a el que busque en el input aquellas informaciones que puedan interesar al/a la destinatario/a. En este caso conocemos únicamente una característica del/de la destinatario/a, que es monitor infantil, pero esta es suficiente para seleccionar varias actividades que puedan interesarle. Como podemos observar hay más input del que es estrictamente necesario para la mediación. En el input hay algunas actividades que no están en absoluto relacionadas con los intereses de un monitor infantil, como la 2. ¿Te inscribes en ofertas de trabajo y no te llaman? y la 6. Prezi y Google Drive. Si el/la mediador/a transmitiera en su e-mail estas informaciones al/a la destinatario/a se le podría penalizar por ello. En este caso las actividades que sería adecuado transmitir serían la 1. Encuentro de jóvenes dinamizadores rurales, la 8. Monográfico. Prevención de adicciones en niños y jóvenes y la 9. Meriendas saludables, ya que estas sí pueden ser de interés para un monitor infantil. Las informaciones complementarias de este input podrían ser la 5. Curso de magia y la 7. Tatuar paredes. El/La mediador/a podría argumentar que si el/la destinatario/a aprende a hacer magia luego puede entretener mejor a los niños y niñas o incluso puede enseñarles algunos trucos. Lo mismo pasaría con el curso de Boa-mistura. Si el monitor aprende esta técnica para tatuar paredes se la puede luego enseñar a los niños y niñas. Valoraremos la selección en función de la argumentación que el/la mediador/a haga de los motivos para esta selección.

En esta tarea se está evaluando el descriptor de mediación Relaying specific information in writing del Companion Volume (North, Goodier, Piccardo, Stathopoulou, 2018: 107). Aunque el input no esté en forma de palabras clave, tampoco hay largas frases que el/la alumno/a mediador/a pueda copiar. Es fácil reformular y ampliar la información para llevar a cabo la transmisión de información específica. El input es, en general, de dificultad inferior al nivel de lengua que se evalúa. Quizás el tema de la prevención de adicciones es de nivel superior a B1. Esto se podría tener en cuenta a la hora de evaluar.

\subsection{Mediación oral de B1: Public Viewing}

Esta actividad de mediación oral está pensada para que se lleve a cabo en parejas. Por lo tanto, disponemos de dos hojas: una para el/la candidato/a A y otra para el/la candidato/a B. En ambas hojas el enunciado es idéntico. Los/as dos candidatos/as tienen las mismas instrucciones para resolver la tarea. Lo que es distinto para cada uno de ellos es el input. 
Public Viewing.

\section{Candidato/a A}

Dispone de 5 minutos para leer la tarea.

Ustedes dos son grandes fanáticos del fútbol y están buscando un lugar público adecuado para ver los próximos partidos del campeonato Mundial. Están buscando algo al aire libre, donde puedan encontrar bebidas especiales. No les gusta nada la cerveza. También quieren asegurarse de obtener un asiento.

Usted encontró estas ofertas en Internet.

\section{Playa 38}

Relajado en tumbonas con arena entre los dedos de los pies y una cerveza fría en la mano. Suena bien, ¿no? EntoncesBeach 38 es el lugar para ti. Hay un estupendo menú "playa 38 " y cócteles al sol. No importa el. clima ya que aquí se retransmiten los juegos en la gran pantalla interior. Habrá alrededor de 250 asientos, la entrada es gratuita. Y lo mejor es que podrás ver el partido desde nuestra fantástica piscina.
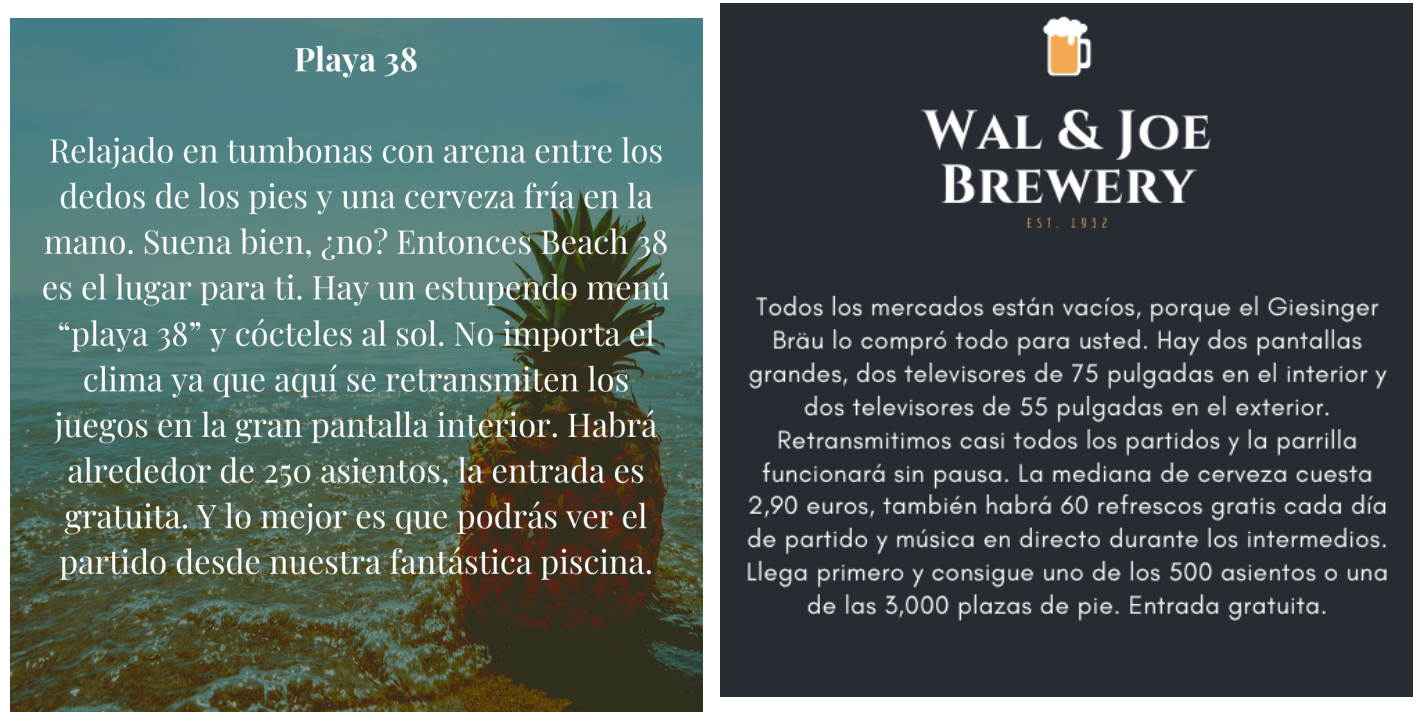

Imagen 3: Playa 38. Diseño de las autoras

Imagen 4: Wal\&Joe Brewery. Diseño autoras Adaptado y traducido de: https://www.mucbook.de/public-viewing-spots-wm-2018-muenchen/

Compare estas ofertas con las de su compañero/a de examen y decida cuál es la mejor para ustedes. Justifique su elección.

La conversación tiene que durar aproximadamente 7 minutos. 


\section{Public Viewing.}

Candidato/a B

Dispone de 5 minutos para leer la tarea.

Ustedes dos son grandes fanáticos del fútbol y están buscando un lugar público adecuado para ver los próximos partidos del campeonato Mundial. Están buscando algo al aire libre, donde puedan encontrar bebidas especiales. No les gusta nada la cerveza. También quieren asegurarse de obtener un asiento.

Usted encontró estas ofertas en Internet.
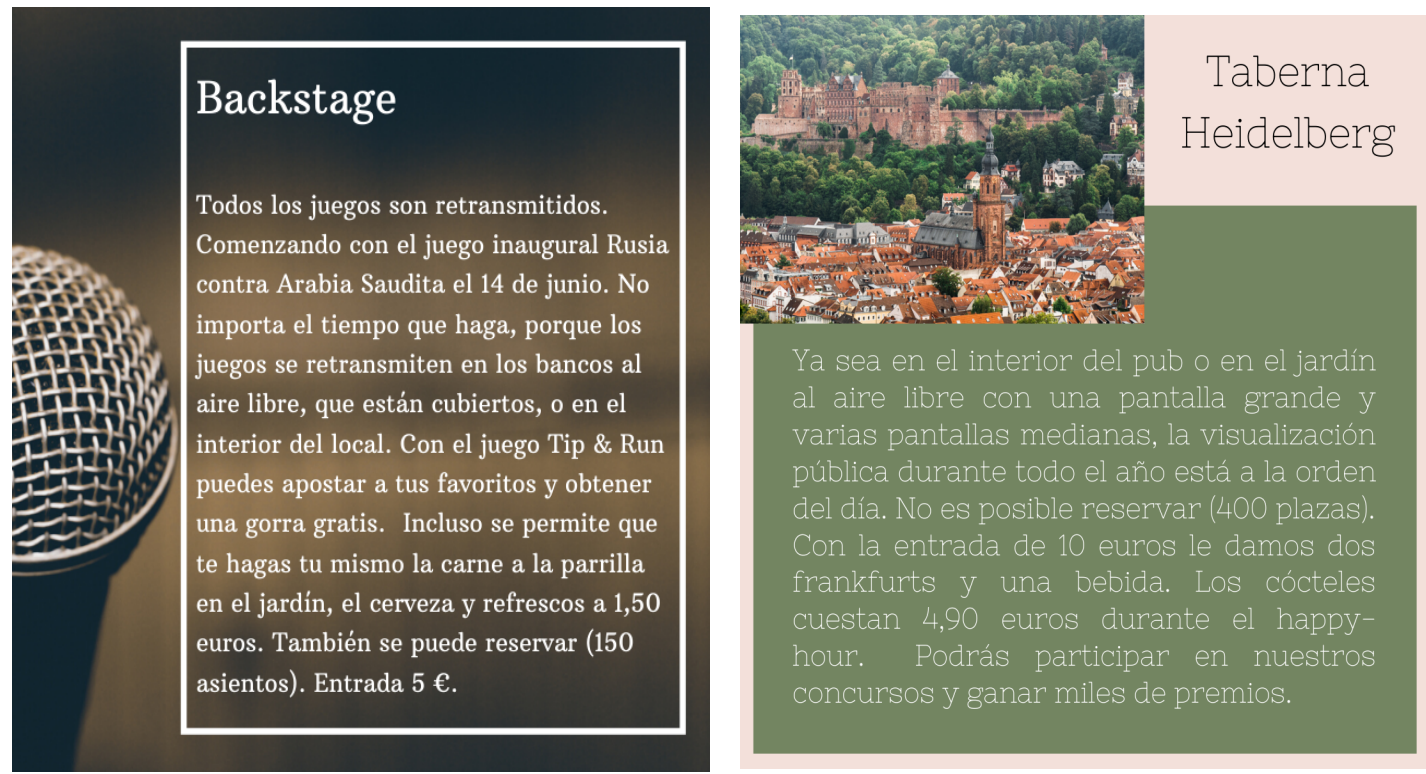

Imagen 5: Backstage. Diseño de las autoras Imagen 6: Taberna Heidelberg. Diseño autoras Adaptado y traducido de: https://www.mucbook.de/public-viewing-spots-wm-2018-muenchen/

Compare estas ofertas con las de su compañero/a de examen y decida cuál es la mejor para ustedes. Justifique su elección.

La conversación tiene que durar aproximadamente 7 minutos.

Aquí hace falta producir una conversación de aproximadamente 7 minutos de duración junto al/la compañero/a porque están buscando un lugar público adecuado para ir a ver el partido de fútbol. Los/as candidatos/as deben transmitir las características de cada sitio que se adecuan a las necesidades.

Para esta tarea se ha escogido un contexto claro, sencillo y bien contextualizado en el que ambos/as candidatos/as son a la vez mediadores/as y destinatarios/as. La cuestión es que cada uno ha encontrado unas informaciones distintas que interesan al otro y mantienen esta conversación para intercambiar informaciones. No hay una demanda 
explícita de ayuda pero ambos tienen las mismas necesidades y colaboran para satisfacerlas.

En este caso conocemos tres necesidades de los/las destinatarios/as: buscan un lugar al aire libre, donde puedan encontrar otras bebidas aparte de cerveza y donde puedan asegurarse de obtener un asiento. Como podemos observar hay más input del que es estrictamente necesario para la mediación. En el input hay algunas actividades que no están en absoluto relacionadas con los intereses de los/las destinatarios/as como las pantallas en el interior, la música en directo, el precio de la mediana de cerveza o la cerveza fría, los concursos, los juegos de apuestas o la piscina. La selección de estas informaciones o la decisión de ir a un sitio u otro en función de estas características debería de ser penalizado por parte del profesor evaluador. En este caso las informaciones que sería adecuado transmitir serían las que están relacionadas con refrescos y bebidas que no sean cerveza, con la retransmisión al aire libre y con la posibilidad de reservar. Las informaciones complementarias de este input serían las relacionadas con el precio de la entrada y con la comida. Ambas informaciones son fácilmente argumentables ya que por un lado es interesante saber cuánto cuesta la entrada en función de lo que ofrece cada espacio y también es plausible que quieran comer algo mientras están ahí. Relacionados con la comida encontramos el menú «playa 38», la carne a la parrilla que puedes hacer tú mismo y las salsichas de regalo con el precio de la entrada. La selección de la información la valoraremos en función de la argumentación que el/la mediador/a haga de los motivos para esta selección.

En esta tarea se están evaluando los descriptores de mediación Processing Text in Speech y Relaying specific information in speech del Companion Volume (North, Goodier, Piccardo, Stathopoulou, 2018: 107). En este caso no es necesario que el input esté en forma de palabras clave, sino que lo que se necesita es un texto que se pueda procesar, reformulándolo y sintetizándolo cuando haga falta. El input es, en general, de dificultad inferior al nivel de lengua que se evalúa.

\subsection{Mediación escrita de B2: La Semana de la Mujer en Chelva}

Esta actividad requiere de la producción de un texto semiformal que el/la alumno/a deberá escribir individualmente para dar respuesta a las necesidades de la AFA.

Usted es el/la director/a del IES Chelva. La Asociación de Familias de Alumnos/as (AFA) le ha propuesto trabajar conjuntamente entre familias y escuela el tema de la igualdad de género con los adolescentes.

Ha encontrado este programa de actividades de la Semana de la Mujer en Chelva. Escriba un correo de 150 palabras aproximadamente a la AFA (y a las familias) exponiendo el contenido del folleto relevante para los adolescentes, explicando por qué les puede ser útil y animando a padres/madres e hijos/as a participar en las jornadas. 


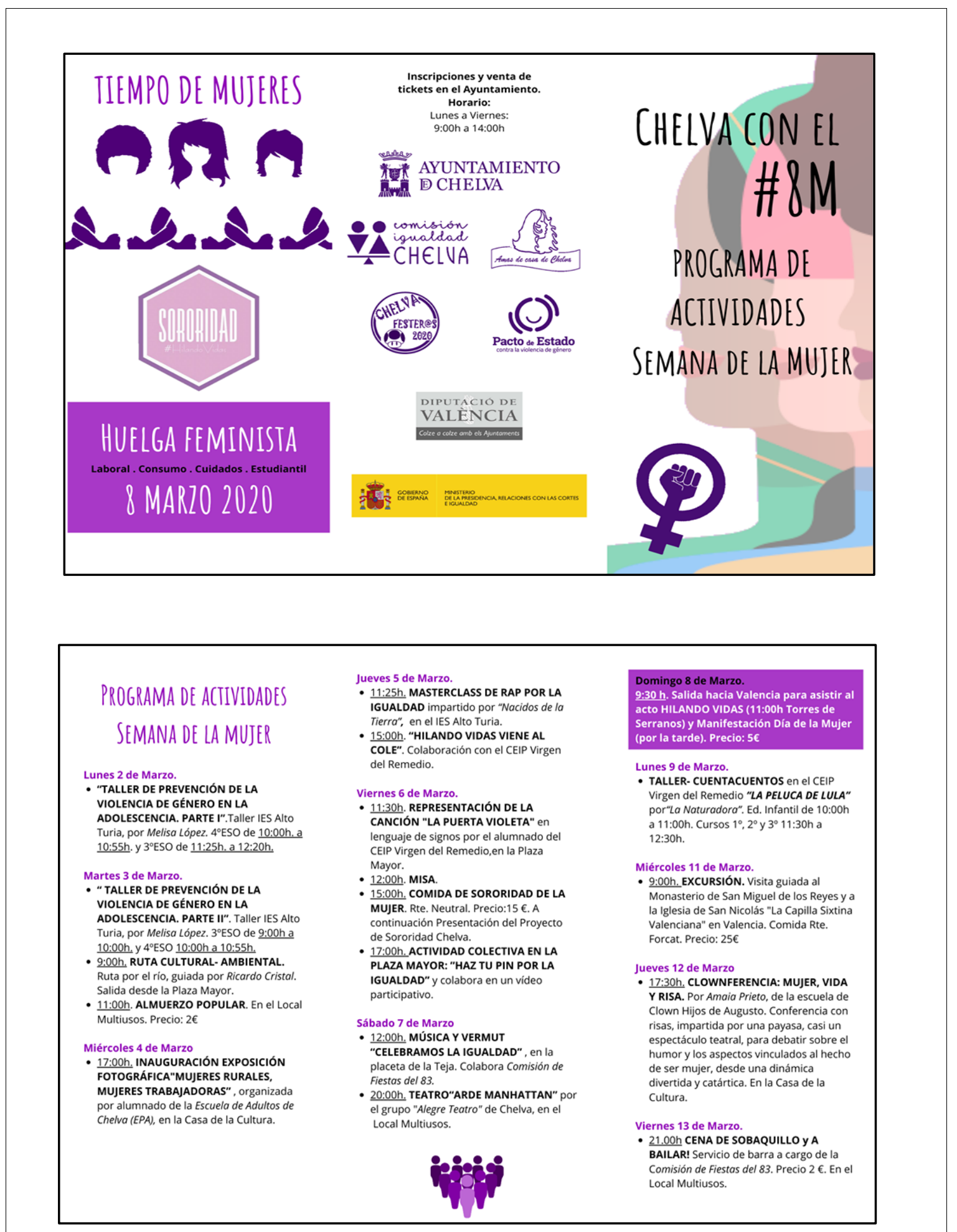

Imágenes 7 y 8: Programa de actividades Semana de la Mujer. Chelva con el 8M. Fuente: https://www.facebook.com/1500176476946981/photos/pcb.2313145285650092/2313143605650260/?type=3\&th eater

El contexto es sencillo y claro: el/la alumno/a, director/a de un centro de secundaria de Chelva (IES Chelva), recibe una solicitud por parte de la Asociación de Familias de Alumnos/as (AFA) para trabajar el tema de la igualdad de género con los jóvenes del 
centro. A partir del programa de actividades de la Semana de la Mujer promovido por el Ayuntamiento (input de la tarea, al que el/la destinatario/a no tiene acceso directo) el/la alumno/a (mediador/a) deberá seleccionar las propuestas más relevantes para los adolescentes y sus familias, motivar su utilidad y animar a la comunidad a participar en las jornadas. El/La mediador/a, pues, deberá seleccionar y adaptar el input a las características y necesidades del/de la destinatario/a. El programa de actos contiene muchas actividades diferentes. Los talleres de prevención de la violencia de género en la adolescencia, los días lunes 2 y martes 3 de marzo podrían ser adecuadas para trabajar la igualdad de género con los/las chicos/as. No sería demasiado pertinente organizar una salida el día 3 a la ruta cultural-ambiental o al almuerzo popular, teniendo en consideración las necesidades concretas de la AFA. Tampoco sería una elección pertinente llevar a los jóvenes a misa el viernes 6 de marzo o a la cena de sobaquillo y al baile el viernes 13, por poner otros ejemplos. Para satisfacer los intereses de la AFA será necesario discernir entre la información imprescindible, la inadecuada y la complementaria según las características del/de la destinatario/a. En algunos casos podría existir una cierta subjetividad en la selección de las propuestas, pero, como ya hemos visto en la tarea de mediación escrita de nivel B1, valoraremos la selección en función de la argumentación que el/la mediador/a sea capaz de hacer. En esta situación se pedirá al alumnado que escriba, en 40 minutos, un texto de 150 palabras de una tipología textual concreta, una carta o correo electrónico, dirigido a las familias de los adolescentes. El texto deberá responder a un registro semiformal, ni demasiado coloquial ni excesivamente formal y distante.

En esta tarea se está evaluando el descriptor de mediación Relaying specific information in writing del Companion Volume (North, Goodier, Piccardo, Stathopoulou, 2018: 107). El/la mediador/a debe utilizar las estrategias de simplificar, reformular, parafrasear y/o ampliar la información para llevar a cabo la tarea y transmitir la información específica.

\subsection{Mediación oral de B2: Ahorro y eficiencia energética}

La siguiente propuesta se realizará en parejas, aunque también se podría llevar a cabo en grupos de tres alumnos/as. La tarea es común para los/as dos (o tres) candidatos/as pero cada uno/a de ellos/as deberá leer un texto diferente $(\mathrm{A} / \mathrm{B} /(\mathrm{C}))$ que le permitirá seleccionar las ideas relevantes para llegar a un acuerdo con el/la compañero/a.

Ustedes son compañeros/as de piso y quieren tomar medidas para ahorrar y ser más eficientes energéticamente. Cada uno ha leído un texto distinto y ponen en común las informaciones obtenidas que les puedan ser más útiles en su caso concreto. Acuerden tres acciones a llevar a cabo a partir de mañana mismo para ser más ecológicos y ahorrar en casa. Disponen de 8 minutos para leer su texto.

La conversación tiene que durar aproximadamente 7 minutos.

Texto A: 


\section{AHORRAR AL MÁXIMO EN TU DÍA A DÍA}

POR MARIONA PÉREZ

En las cosas de casa, o en la compra, o cuando salgas a darte un capricho, contrata y compra de forma inteligente y te sentirás mucho mejor.

Cuando te toque renovar electrodomésticos y bombillas, no lo dudes, cámbiate a los de bajo consumo.

Es un clásico que no falla. Los

electrodomésticos $\mathrm{A}+++$ son los que menos consumen, y en bombillas, el tipo más recomendado es el LED.

A parte hay un millón de consejos para ahorrar energía en casa: apagar las

luces al dejar una habitación, mantener limpias las lámparas un foco sucio (ipierde 50 por ciento de su luminosidad!), utilizar sensores de iluminación, desconectar el cargador al finalizar la carga de la batería del móvil (porque sigue consumiendo)

configurar en modo ahorro de energía los equipos que no se pueden apagar...

¿Sabías que cada grado que se sube la calefacción representa un $7 \%$ de consumo añadido? Pues sí, es recomendable que mientras no estés en casa y durante la noche, mantengas una temperatura "aceptable" de $15^{\circ}$, nunca más de $17^{\circ}$, y que cuando estés, no la subas más allá de $20^{\circ} \mathrm{o} 21^{\circ}$. No la (apagues, el coste de calentar una habitación fría es superior al de mantenerla a una temperatura constante.

Ojo con los gastos de farmacia: ten en cuenta que hay medicamentos de idéntica composición, pero con precios muy distintos según las marcas. Presta atención también a las ofertas online, sobre todo en los restaurantes y las compras de moda, cada vez hay más descuentos por Internet que puedes aprovechar. Y restringe el uso de las tarjetas de crédito. No siempre son buenas... favorecen el derroche y suponen intereses.

Imagen 9: Ahorrar al máximo en tu día a día. Diseño de las autoras.

Adaptado de: https://www.proximaati.com/hogar/ahorro/compra-inteligente-ahorra-al-maximo-dia-adia? gclid $=$ CjwKCAjw3-

Texto B:

\section{CONSEJOS PARA LLEGAR A FIN DE MES}

Por Jacobo Triviani

Con los tiempos que corren, nadie está para tirar el dinero. Por eso os vamos a dar algunos consejos prácticos para poder llegar a fin de mes y, en algunos casos, ayudar al planeta.

En casa, coloca la nevera a 15 centímetros de la pared para una mejor circulación del aire del motor y evita abrir y cerrar la puerta reiteradamente, ya que el frío se escapa... Cuando tengas que lavar, usa la lavadora a plena carga y en programas cortos y evita la función secado, que es la que más gasta.

Si tienes aire acondicionado, utilízalo con una temperatura de $21^{\circ}$. En los dormitorios se puede rebajar entre $3^{\circ}$ y $5^{\circ}$. Si puedes, aprovéchate de los planes renove de ayudas para sustituir las ventanas antiguas por otras más aislantes, jtener unos buenos cerramientos puede cambiar mucho tu factura! $Y$ también tener unas buenas cortinas y alguna alfombra.

Cuando vamos a la compra, hazte todas las tarjetas de fidelización gratuitas que puedas: casi siempre te dan algún descuento o ventaja. Con buen ojo puedes llegar a ahorrar un $30 \%$. Haz una lista previa, ten claro qué productos necesitas y cíñete a ellos. Cuando elijas tus artículos de limpieza, apuesta por productos inteligentes y eficaces. A veces, pagar un poco más compensa porque también cunde mucho más ya que sus fórmulas son diferentes, más poderosas, eficaces y respetuosas con el ambiente que las de otros productos, fruto de años de investigación e innovación imparable. No hay que olvidar que a veces, lo barato sale caro.

Imagen 10: Consejos para llegar a fin de mes. Diseño de las autoras. Adaptado de: https://www.gestarcoop.com/novedades/noticias/34-mundo-cooperativo/196-10consejos-para-ahorrar-energia-electrica.html

El alumnado, que en este caso comparte apartamento, ha tomado la decisión de informarse y poner en común sus ideas para llegar a tres acuerdos concretos que les permitan economizar y ser más amables con el planeta. Cada alumno/a dispone de 8 
minutos para leer un texto distinto (A/B) en el que confluyen algunas iniciativas de ahorro imprescindibles para ellos/as, otras complementarias y otras irrelevantes. De este input (A/B) se deberán seleccionar las ideas pertinentes para llevar a cabo la tarea. Vamos a poner unos ejemplos: del texto A, el/la alumno/a puede seleccionar un cambio de bombillas a LED (de bajo consumo), acordarse de apagar las luces, mantener limpias las lámparas, dejar a una cierta temperatura de la calefacción o desconectar el cargador del móvil. No tan factible sería renovar los electrodomésticos de la casa de inmediato, ya que la consigna de la tarea insta a acordar tres acciones a llevar a cabo "a partir de mañana mismo". En cambio, del texto A, no serían en absoluto seleccionables los gastos de farmacia, ni las ofertas de restaurantes y moda en línea, ni el uso limitado de tarjetas de crédito, ya que estos últimos aspectos, si bien sirven para ahorrar dinero, no se corresponden al hecho de ser más eficientes energéticamente, por lo que resultan aspectos inadecuados. Si el/la candidato/a A transmite a B estas ideas, no estará demostrando que es capaz de seleccionar toda la información relevante del input y adaptarla de manera eficaz al/a la destinatario/a y a la situación comunicativa. Asimismo, el/la alumno/a B, puede sugerir al/a la compañero/a que aparten la nevera de la pared y eviten abrir y cerrar la puerta repetidamente, que usen la lavadora a plena carga y en programas cortos, que utilicen el aire acondicionado con una temperatura determinada, o que compren artículos de limpieza respetuosos con el ambiente. Para el objetivo de la tarea, en cambio, no es pertinente hacerse con las tarjetas de fidelización de los supermercados o ceñirse a la lista de la compra.

Desde el momento que A lee un texto y B otro texto diferente, resulta evidente la necesidad de mediar de los/as candidatos/as, ya que no tienen acceso directo al input de su compañero/a de piso. Tratándose de un nivel B2, los textos en cuestión son de una cierta longitud (250-300 palabras aproximadamente), pero vemos de nuevo que el nivel de lengua del input es de dificultad inferior al del nivel de dominio del alumnado, que ejerce a la vez de mediador/a y de destinatario/a de la mediación. Hay más input del que es estrictamente necesario para resolver la tarea para posibilitar la selección y la adaptación del input a las características y necesidades de la situación comunicativa, que es precisamente el llegar a la toma de acuerdos con la finalidad de ser más eficientes energéticamente y ahorrar dinero en las cosas de casa.

En el enunciado de la tarea vemos unas instrucciones claras y transparentes, redactadas de manera sencilla, que facilitan la comprensión de lo que se tiene que hacer y los tiempos de los que se dispone. La tarea está bien contextualizada: se deben compartir las informaciones del input que puedan ser más útiles para los/as compañeros/as de piso. La producción, para evaluar el descriptor de mediación Processing text in speech del Companion Volume (North, Goodier, Piccardo, Stathopoulou, 2018: 110), debe ser una conversación de unos 7 minutos, en los que el alumnado demuestre, no solo su capacidad de seleccionar, estructurar la información y utilizar estrategias lingüísticas en modo apropiado, sino también de colaborar activamente y facilitar la interacción para llevar a cabo la tarea.

\subsection{Mediación escrita de $\mathrm{C} 1$ : Las sevillanas}

Esta actividad responde a la actividad Processing text in Writing del Companion Volume 
(North, Goodier, Piccardo, Stathopoulou, 2018: 110).

Un/a amigo/a suyo está haciendo una investigación sobre las danzas en España y le ha pedido ayuda con las sevillanas. Le interesa especialmente el origen de cada danza.

Usted ha visto un reportaje de 10 minutos en Canal Sur que cree que le podría ser útil. Escriba un texto en el que resuma los puntos más destacados del vídeo relacionados con los intereses concretos de su amigo/a.

(175 palabras aproximadamente)

INPUT: El origen de las sevillanas, Canal Sur, Olalla D., YouTube https://www.youtube.com/watch?v=-t6w_bi7fIE

Contenido del input: En el vídeo se relata el origen de las sevillanas hace cuatro siglos y su desarrollo musical a partir de entonces hasta el siglo XX. Explica su éxito entre los años 60 y 90 del siglo XX y hace un repaso musical de los grupos de esas épocas.

En este caso el/la alumno/a (mediador/a) deberá facilitar la información contenida en el reportaje de Canal Sur sobre las sevillanas (input) a su amigo (destinatario/a), que, por problemas de tiempo, no tiene acceso a la información y ha solicitado ayuda para poder llevar a cabo su investigación sobre las danzas en el mundo y en especial sobre los orígenes de cada danza (contexto). El texto que el/la alumno/a deberá producir es un resumen de 175 palabras con las ideas del video que son relevantes para la investigación de su amigo.

En el input hay más información de la que necesita el/la destinatario/a. De hecho, en el vídeo hay mucha información que se refiere a los grupos musicales que han tocado y cantado sevillanas a partir de los años 60. Se trata de una información que no tiene que ver con el objetivo de la investigación del/de la destinatario/a, por lo tanto se puede omitir o quizás sintetizar. La selección de la información requerida por el/la destinatario/a se podría limitar al relato de los siglos XVI y XVII, que se refieren en sentido estricto a los orígenes de esta danza. Sin embargo, hablar de la historia de este baile durante los siglos XVII, XIX y XX puede ser útil para la investigación. Son las necesidades del/de la destinatario/a que determinan la selección de la información contenida en el vídeo. En consecuencia, no se trata de elaborar un resumen del contenido mismo, sino que se trata de escribir un texto ad hoc para nuestro amigo y posiblemente con una estructura académica, ya que está hecho para una investigación.

\subsection{Mediación oral de C1: Mural Freedom de Millo}

Entre las actividades de mediación propuestas al alumnado, según el Companion Volume (North, Goodier, Piccardo, Stathopoulou, 2018: 115), hemos escogido Expressing a personal response to creative texts para la mediación oral de nivel $\mathrm{C} 1$. Estos textos creativos pueden ser de diferentes tipologías e incluir variedad de formatos, incluyendo la literatura. Así, podemos trabajar con obras de arte (pinturas, grafitis, carteles, 
esculturas, etc.) y textos escritos (poemas, narrativa breve o microrrelatos, extractos de novelas, etc.).

\section{Ejemplo 1}

Ustedes están de viaje y les han recomendado visitar esta obra de arte urbano titulada Freedom del artista Millo. Ahora que están justo delante desean intercambiar sus impresiones. Háganlo utilizando los puntos siguientes y otros si lo consideran oportuno:

- ¿Qué reacción les provoca la obra?

- ¿Qué simbología tiene para ustedes?

- ¿Qué importancia tiene este grafiti según ustedes?

- ¿A qué público creen que va destinada la obra?

Disponen de 2 minutos para observar la imagen. La conversación tiene que aproximadamente 5 minutos.

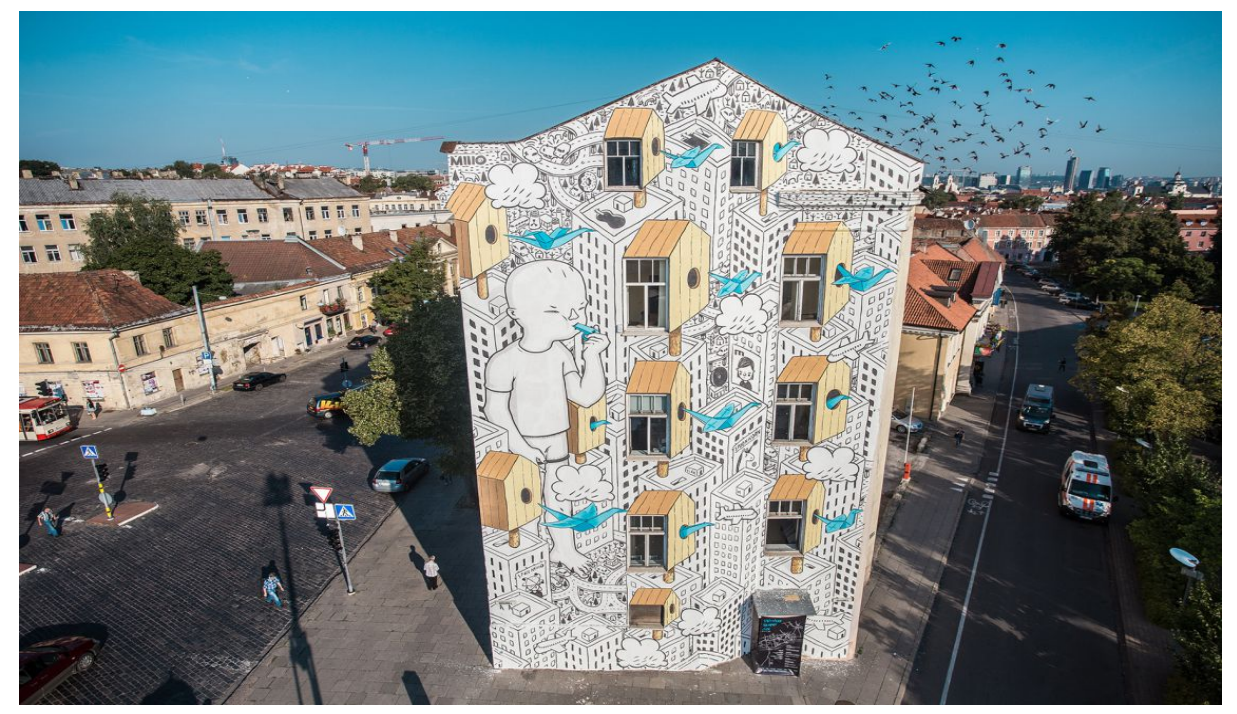

Imagen 11: Mural Freedom del artista Millo, Vilnius, Lituania.

Fuente: https://www.millo.biz/portfolio_page/freedom-vilnius-lithuania/ 


\section{Ejemplo 2}

\section{w w 숭}

同 $\nabla \backslash 18: 59$

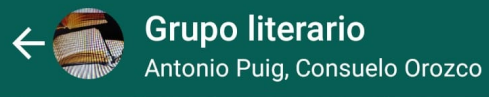

Consuelo Orozco

Os paso un microrrelato. A ver qué os parece.

06:59 p. m

Trasplante

(de Manuel Pastrana Lozano)

De pronto, el anciano cayó en cuenta de que su corazón había dejado de palpitar y de que ya no estaba en su lugar habitual, el lado izquierdo de su pecho. Como que se hubiese evaporado. No sintió ningún pulso. Con su mano ya temblorosa se palpó el otro costado y tampoco percibió latidos. Nada, todo igual, ningún estremecimiento en su pecho que pudiese indicarle que aún estaba vivo. Empezó a respirar con dificultad y se sintió ahogado. $Y$ antes de morir -todavía lúcido-, recordó que su corazón siempre había estado unido al de ella -ahora en el más allá-, y ambos latidos resonaron fuertes, definitivamente inseparables.

Genial! Muchas gracias! 06:59 p. m

표마pe a message

\section{:} १ microrrelato de Manuel Pastrana Lozano a través de un Grupo literario al que pertenecen. Desean intercambiar sus impresiones al respeto. Háganlo utilizando los puntos siguientes y otros si lo consideran oportuno:

- ¿Cómo interpretan la obra?

- ¿Qué reacción les provoca?

- ¿Qué importancia tiene para ustedes la obra?

-¿Cómo interpretan el personaje?

- ¿En qué estado emocional se encuentra el personaje?

-¿Cómo interpretan el argumento?

Disponen de 2 minutos para leer el te

La conversación tiene que durar aproximadamente 5 minutos.

Imagen 12: Conversación de Whatsapp. Diseño de las autoras. Fuente: https://narrativabreve.com/2018/04/dos-microrrelatos-muy-breves.html

Es importante subrayar que se trata de desarrollar una conversación que no implica referencias culturales específicas, técnicas o estéticas referentes al mundo del arte o de la literatura, sino que se trata de reproducir un intercambio de opiniones que se podría tener durante un viaje, una visita a una exposición, una lectura, etc. En este sentido, en el primer ejemplo, hemos escogido un grafiti que es una obra de carácter y temática general y los puntos que se sugieren para desarrollar la conversación delimitan claramente el ámbito de la conversación misma.

Por lo tanto, delante del input de la prueba tenemos que esperar que en primer lugar se exprese una reacción personal que dado el tipo de obra y su temática, no se limite a una evaluación de gusto (me gusta/no me gusta), si no que indique una reacción que tenga que ver con lo que supuestamente es el mensaje de este grafiti. Es evidente que la selección de la información no es tan clara como en los otros modelos de la prueba: en 
todo caso, si por ejemplo se hace referencia a la calle o a la meteorología, la selección no es apropiada. En cambio, es importante referirse al chico que toca el silbato, a los edificios que se transforman en casas para pájaros, a los pájaros mismos que salen volando de las casas, etc. El/La destinatario/a y sus necesidades tampoco están definidos como en las tareas de los otros niveles. De hecho, no se trata de responder a unas necesidades, sino más bien de situarse en un contexto y expresar las propias consideraciones, reflexionar sobre el significado y la importancia del grafiti y además indicar su posible público o impacto. En estos casos el papel del input es fundamental para que la mediación tenga éxito.

Las mismas consideraciones se pueden repetir para el texto literario del ejemplo 2.

\section{Conclusiones}

Queremos terminar este artículo subrayando nuestro alegato en favor de las tareas de mediación intralingüística ya que hemos podido evidenciar que nos permiten evaluar los descriptores del Companion Volume (North, Goodier, Piccardo, Stathopoulou ,2018: 104) de una manera exhaustiva. Hemos podido constatar analizando producciones que las actividades de mediación intralingüísticas permiten desarrollar aspectos más ricos de matices que las interlingüísticas, aunque no siempre muy evidentes. El diseño de la tarea de mediación, ya sea interlingüística o intralingüística, requiere, de hecho, más atención para que no se convierta en una tarea únicamente de interacción. Al mismo tiempo, en el momento de la ejecución de la tarea de mediación, se tiene que prestar especial atención a las dinámicas de interacción, ya que en mediación interlingüística no se trata únicamente de transferir un mensaje de la L1 a la L2, sino más bien de activar actitudes más complejas en el ámbito personal y sociocultural (empatía, referentes culturales...).

En consecuencia, el reto de diseñar tareas de mediación interlingüísticas requiere, en primer lugar, un atento análisis: por un lado, de las características de mediación y, por el otro, de los métodos de evaluación.

En este sentido, pensamos que de todas las características de las tareas de mediación que hemos expuesto, se tiene que hacer especial énfasis en la selección de los contenidos que el/la destinatario/a necesita. Recordemos que sin el aspecto de la selección el/la mediador/a puede limitarse a llevar a cabo un resumen (o una síntesis, o una reformulación, o un parafraseo, etc.) del input, mientras que en la mediación lo que se requiere del/de la mediador/a es que seleccione del input aquellas informaciones relevantes para el/la destinatario/a. A nuestro entender, queremos insistir, una tarea sin selección no es una buena tarea de mediación. Diseñar una buena tarea de mediación tiene que ver también con los criterios que se aplican a su evaluación. Creemos que la evaluación es uno de los aspectos más delicados de la mediación, ya que se trata de pasar de la conceptualización a la práctica, haciendo de alguna forma visible todo el proceso que está detrás de las actividades de mediación. Por eso, escoger entre rúbricas holísticas y analíticas no es sencillo y tendremos que investigar y practicar más en este ámbito, sin olvidar que hará falta una validación de los criterios de evaluación / corrección.

En este artículo, nos hemos centrado en las tareas de mediación en las pruebas de certificación, pero consideramos importante explorar también las posibilidades que 
ofrece la mediación en el aula. No es lo mismo trabajar la mediación en clase, donde el campo para la experimentación es mucho más amplio, que elaborar tareas de mediación para una evaluación o un examen.

Por otro lado, el análisis de producciones de los/las alumnos/as ya sea en mediación escrita u oral, nos puede dar cuenta de las estrategias y recursos lingüísticos requeridos en los diferentes tipos de tareas y en los distintos niveles de dominio de la lengua. Aquí también se abre un interesante trabajo de campo, que crea una vez más una sinergia positiva y una constante retroalimentación entre aula y reflexión teórica. En este sentido, estamos convencidas que la mediación es una excelente oportunidad de mejorar las pruebas de certificación y el trabajo en el aula, ya que fomenta el desarrollo del aprendizaje competencial y permite realizar tareas y actividades más auténticas y motivadoras.

\section{Bibliografía}

Cantero Serena, F. J., De Arriba García, C. (2004). «La mediación lingüística en la enseñanza de lenguas», Didáctica. Lengua y literatura, (16), pp. 9-21.

CAÑAda Pujols, M., FANTAuZZi, S., TRUllàs Soler, M. (2019). «La mediació a les EOI de Catalunya: certificació, avaluació i docència», InterEOI, 15, pp. 105-128. Recuperado de: https://issuu.com/eoicat/docs/inter_eoi_n15

COUNCIL OF Europe. COUNCIL FOR CUlTural CO-OPERATION. EDUCATION COMMITTEE. MOdERn LANGUAGES Division (2001). Common European Framework of Reference for Languages: learning, teaching, assessment. Cambridge: Cambridge University Press.

DENDRINOS, B. (2006). «Mediation in communication, language teaching and testing», Journal of Applied Linguistics, 22, pp. 9-35.

LANDESREGIERUNG SCHLESWIG-HOLSTEIN (2018, Agosto). Bewertungsbogen schriftliche Sprachmittlung Deutsch - Fremdsprache (Abitur 2018 - NEU 28.08.2017). Ministerium für Bildung, Wissenschaft und Kultur. URL https://za.schleswigholstein.de/zabDokumente/?view=100\&path=Abitur $\mid 2018$

North, B., Goodier, T., Piccardo, E., Stathopoulou, M. (2018). CEFR Companion Volume with new descriptors. Council of Europe, Strasbourg. Recuperado de: URL https://rm. coe. int/cefr-companion-volume-with-new-descriptors-2018/1680787989.

SÁNCHEZ CASTRO, M. (2013). "La mediación en clase de ELE: una actividad potenciadora de la competencia plurilingüe e intercultural». En Plurilingüismo y enseñanza de ELE en contextos multiculturales: XXIII Congreso Internacional ASELE (pp. 791-801). Asociación para la Enseñanza del Español como Lengua Extranjera.

STATHOPOULOU, M, (2014). «The linguistic characteristics of KPG written mediation tasks across proficiency levels». En Major Trends in Theoretical and Applied Linguistics 3 (pp. 349-366). Sciendo Migration.

StATHOPOUlOU, M. (2016). «From 'languaging' to 'translanguaging': Reconsidering foreign language teaching and testing through a multilingual lens», Selected papers on theoretical and applied linguistics, 21, pp. 759-774. 
Trovato, G. (2013). «La mediación lingüística como competencia integradora en la didáctica de E/LE: una aproximación a las tareas de mediación oral y escrita», Mediterráneo (Revista de la Consejería de Educación en Italia, Grecia y Albania), 2(5), pp. 104-119.

\section{Legislación}

CATALunYa. Decreto 4/2009, de 13 de enero, por el que se establece la ordenación y el currículum de las enseñanzas de idiomas de régimen especial (DOGC, núm. 5297, 13.01.2009).

ESPAÑA. Real Decreto 1041/2017, de 22 de diciembre, por el que se fijan las exigencias mínimas del nivel básico a efectos de certificación, se establece el currículo básico de los niveles Intermedio B1, Intermedio B2, Avanzado C1, y Avanzado C2, de las Enseñanzas de idiomas de régimen especial reguladas por la Ley Orgánica 2/2006, de 3 de mayo, de Educación, y se establecen las equivalencias entre las Enseñanzas de idiomas de régimen especial reguladas en diversos planes de estudios y las de este real decreto (BOE, núm. 311, 23.12.2017).

ESPAÑA. Real Decreto $1 / 2019$, de 11 de enero, por el que se establecen los principios básicos comunes de evaluación aplicables a las pruebas de certificación oficial de los niveles Intermedio B1, Intermedio B2, Avanzado C1, y Avanzado C2 de las enseñanzas de idiomas de régimen especial (BOE, núm. 11, 12.01.2019). 